\title{
La guerra kumiai en las postrimerías del siglo XVIII y la fundación de San Miguel Arcángel
}

\author{
David Zárate Loperena \\ Dirección de Asuntos Culturales \\ Gobierno del Estado de Baja California
}

\section{Resumen}

Este artículo se basa en una revisión de documentos históricos que manifiestan la resistencia que opusieron los kumiai a ser sometidos por los españoles. Los kumiai, un grupo aguerrido y rebelde el cual es objeto de este trabajo, llegaron en las postrimerías de la migración de los grupos de lengua yumana, ocupando la porción sur del Estado de California y el norte de la península. La fundación de la Misión de San Miguel Arcángel marcó el término de la insurrección indígena de los kumiai. Los años restantes del siglo XVIII transcurrieron en relativa calma, salvo algunos incidentes aislados.

Palabras clave: kumiai, yumanos, Misión San Miguel Arcángel, resistencia.

\begin{abstract}
The foundation of this article is the review of historical documents that prove the resistance opposed by the Kumiai Indians against the subjugation from the Spaniards. The Kumiai was a hardened and rebel group, the object of this research, who arrived when the last migratory groups of the Yuman language arrived to this region. This group was established in the southern part of the State of California and the North of the Peninsula de Baja California. The foundation of the Mission of San Miguel Arcángel put to an end to the insurrection of the Kumiai Indians. This region lived a relative peace during the last years of the XVIII century, except for some isolated incidents.
\end{abstract}

Keywords: Kumiai Indians, Yuman Indians, Mission of San Miguel Arcángel, resistance. 


\title{
LA GUERRA KUMIAI EN LAS POSTRIMERIAS DEL SIGLO XVIII, Y LA FUNDACION DE SAN MIGUEL ARCANGEL
}

\author{
Por \\ David Zárate Loperena*
}

Los últimos grupos de lengua yumana que penetraron a la península de Baja California, lo hicieron a partir del año 1000 de nuestra era, y así continuaron llegando por espacio de 500 años. Los kumiai, objeto de este trabajo, llegaron en las postrimerías de la migración y por lo tanto les da una residencia tardía. Ellos pasaron a ocupar la porción sur del estado de California y el norte de la península, probablemente hasta lo que hoy es el poblado de San Vicente. En este territorio se hablaron cuando menos cuatro variantes dialectales.

Al momento del contacto europeo, los indigenas apenas iniciaban el desarrollo de una tecnología que les permitía aprovechar los tres ecosistemas que habitaban: la costa, montaña y desierto. Su organización social la constituían pequeñas bandas semisedentarias de linaje patrilineal, mismas que practicaban una estricta exogamia; por tanto, el número de sus miembros difícilmente rebasaba los cien individuos (Owen, 1966). Históricamente se conocen por lo menos 25 familias o shimuls, de las cuales aún quedan seis o siete. Cada shimul estaba políticamente guiado por un kulpay o jefe, un orador(kulpay tium), y un hechicero o cusiay; sobre quien recaía la responsabilidad del bienestar de la banda, la observancia de las antiguas costumbres y la apropiada ejecución de las ceremonias iniciáticas y funerarias.

Los kumiai sólo se organizaban tribalmente durante la guerra, tal es el caso de Jatñil o Caballo Negro, de la banda Mishkwish, quien por más de cincuenta años comandó a los indígenas de la costa y de la montaña de J'cum (Jacumé) (Meigs, 1936) hasta el desierto; otras bandas kumiai estaban aliadas con los cuchán de la ranchería de Xuksil, que eran enemigas de Jatñil.

$\mathrm{Al}$ igual que los otros grupos étnicos del norte de la península, los kumiai no pueden ser considerados como belicosos si son comparados con las tribus del delta del Colorado. Con esto no queremos decir que desconocieran la guerra, pues al contrario, fueron ellos precisamente los que opusieron mayor resistencia al reaccionar violentamente a la fundación de misiones en las Californias (Zárate, 1984).

Sobre el carácter de los kumiai existen bastantes opiniones: para Pedro Fages, comandante militar de la Antigua California, éstos resultaron "más broncos que ningún otro grupo indígena. . ."(Fages, 1787a). Fray Luis de Sales opinó: "los gentiles son algo altivos y siempre inclinados a hacer el mal . ..",

\footnotetext{
* Historiador de la Dirección de Asuntos Culturales del Gobierno del Estado de Baja California.
} 
posteriormente especifica diciendo: "los de Santo Domingo y San Vicente son inquietos, soberbios y revoltosos; y éstos de San Miguel, entre quienes vivo, . . . tienen un genio recio, indócil, altivos de sobre manera, valientes y guerreros, y en todo tiempo han dado que hacer a la tropa. . ." (Sales, 1960). Otro misionero, el padre Verger, en un informe dirigido a Lanz de Casanfonda, fiscal del Consejo de Indias, le informó: "estos infelices dieguinos son más hábiles y más altivos ... ni han prometido obediencia a nuestro Monarca, ni dan señas de quererlo hacer, ni de recibir Nuestra Santa Ley" (Verger, 1771).

Los de San Diego, opinaba el capitán Rivera y Moncada, "no desdicen las muestras que observéde las obras que han executado, pareciéndome capaces de no dejar Padre a vida"; y termina diciendo: "si yo les llevara el cordel más floxo, sería que quisieran armarse con el santo y la limosna, haciendo desprecio de mi y de todos"(Burrus, 1967). Otros señalaban que entre los kumiai "no subsiste la afabilidad y docilidad. .." (Expediente sobre el Mejor Establecimiento de las Nuevas Misiones de California y Subsistencia de las Antiguas de Aquella Península, 1772); o bien que son de "mala intención"(Fages, 1787a). Algunos más se quejaban de que los nativos eran orgullosos, rencorosos, jactanciosos, dados a la burla y a la riña; apasionados por mantener las antiguas costumbres y difíciles de sujetar. En fin, sólo JuníperoSerra vio algo distintoen ellos, al dejar asentado en su bitácora "su bello talle, deporte, afabilidad y alegría nos ha enamorado a todos . . . me han robado el corazón”. (Gómez Canedo, 1969).

\section{Kapkan Viũup. Ir a la guerra}

Los enfrentamientos armados eran generalmente ocasionados por venganzas personales o familiares. También se daban por causas de hechicería o simplemente cuando se sorprendía a un enemigo en territorio considerado como propio (Luomala, 1978). Estos motivos podian llevar a largas guerras y crear enemistades centenarias como la de los cuchán y los cucapá, o bien crear ligas o alianzas con las tribus del Colorado; las cuales ya estaban bien establecidas a la llegada de los europeos (Forbes, 1975).

Poca es la información que se tiene sobre las guerras indígenas anteriores a la conquista de las Californias, por lo que nos limitaremos a los datos etnohistóricos del siglo XVIII, que si bien son escuetos y con frecuencia confusos, nos dan una idea de las armas utilizadas por ellos, sus tácticas y la impresión causada en los españoles.

Los kumiai no hicieron esperar mucho a los soldados y misioneros, pueséstos aún no cumplían un mes de haberse establecido cuando sufrieron el primer ataque, que resultó desarticulado y con poca organización para combatir las armas españolas. Así, el 15 de agosto de 1769 trajo muertes para ambos bandos y la peor parte le tocó a los indígenas aunque éstos dieron muerte a un soldado de cuera y al paje de Junípero Serra, de nombre José María, nativo de la misión de Loreto. También fueron heridos el padre Vizcaíno, un indio californio y el herrero que, según Palou, al grito de "Viva la fe de Jesucristo y mueran estos perros enemigos de ella”, fue alcanzado por una flecha (Gómez Canedo, 1969). 
Mucha impresión causaron algunas armas de los nativos a los defensores de la misión de San Diego, sobre todo "las macanas de maderaen forma de sables que cortan como el acero, y otras como porras y mazos con que hacen mucho estrago" (Gómez Canedo, 1969).

El 5 de noviembre de 1775, de nuevo es atacada la misión de San Diego; la conspiración y el asalto fueron dirigidos por los indígenas neófitos. En esta ocasión se notó una mejor organización, pues de acuerdo con Palou "convocáronse más de mil indios, muchos de ellos entre sí no conocidos, ni jamás vistos. . . los cuales pactaron en dividirse en dos trozos, para caer uno en la misión y otro al presidio. Así pactados y bien armados de flechas y macanas, se encaminaron a poner en ejercicio su depravado designio" (Gómez Canedo, 1969). Los kumiai tuvieron una falta en su coordinación y sólo actuaron con éxito en el asalto al sitio misional, incendiando las habitaciones de los padres y soldados. También el fuego acabó con la herrería y carpintería; además, la iglesia sufrió graves daños, por lo que hubo necesidad de construirla nuevamente.

Fue tal la cantidad de indígenas y la violencia de éstos, que lograron confundir a los defensores, quienes ante la "lluvia de piedras, flechas y tizones de lumbre que les fueron arrojados. .." (Burrus, 1967), no pudieron reponerse del ataque y en poco tiempo quedaron heridos tres soldados, un cabo, el carpintero (quien falleció a los pocos días), el herrero que recibió dos flechas y cuyo cuerpo cayó en la lumbre quedando totalmente quemado, y por último fray Luis Jayme, quien fue sorprendido y llevado a un zanjoncito, en donde fue brutalmente ejecutado con una gran cantidad de flechas y macanazos (Expediente. . ., 1772). Seguramente, los soldados también hubiesen fallecido de no haber sido protegidos por "la cuera".

Se considera importante destacar que los kumiai tenían un excelente servicio de información y correos, que comenzaba en Wi Ipok, localizado en La Rumorosa, para terminar en las costas del Pacífico. Además, contaban con centinelas en todos los sitios considerados como estratégicos; y posteriormente elaboraron una red de espionaje - si así se le puede llamar - en todas las misiones franciscanas y dominicas. También fueron excelentes diplomáticos al lograr una gran cantidad de alianzas para asegurar sus éxitos militares (Shipek, 1982).

El territorio kumiai se vio invadido de sitios misionales; además de San Diego, se construyó la asistencia de Santa Isabel;y en Baja Californialos hubo de norte a sur: El Descanso, San Miguel Arcángel, Guadalupe, Santo Tomás, Santa Catalina y San Vicente. Queremos incluir aquí el poblado de San Pedro y San Pablo Bicuñer, que se levantó junto a la ranchería Xuksil, de los indígenas cuchán, y que actualmente ocupa la población de Los Algodones. Este pueblo, junto con el de La Concepción, fueron destruidos el día martes 17 de julio de 1781 por los cuchán y sus aliados, los kumiai del desierto y los kojuana. Las muertes de los cuatro frailes: Garcés, Berreneche, Díaz y Moreno, fueron recibidas con mucha gravedad por el gobierno de la Nueva España. Dos de ellos fueron ejecutados con macanas y mazos, Moreno fue decapitado. También encontraron la muerte el capitán Fernando Rivera y Moncada, 31 soldados y 20 colonos, y de 
acuerdo con un informe posterior, 20 mujeres y 20 niños. Los indígenas hicieron 76 prisioneros, se llevaron 192 caballos y vacas de los colonos, 204 borregos y 42 caballos de los soldados de cuera (Forbes, 1975). No hay seguridad de que estos datos incluyan al cabo Pascual Bailón y su escolta de nueve soldados, quienes llegaron a Bicuñer en su travesía a San Gabriel, Alta California, a quien los cuchán también dieron muerte, obteniendo cuantiosas provisiones y ganado. Este desastre causó graves trastornos a la política expansionista de España, que jamás logró tener un control efectivo sobre esta región de vital importancia para el desarrollo de la Alta California.

El avance misional de la península también se vio afectado a causa de este descalabro, pues les tomaría seis años fundar otra misión, que fue la de San Miguel Arcángel, en 1787. Había pues que restablecer y fortalecer lo conquistado. Otra causa que contribuyó con el estancamiento de la cristianización de la frontera fue la epidemia de viruela en 1781, que acabó con más de la cuarta parte de la población indígena de la región de San Vicente.

Ahora pasaremos a otra forma de guerra que los kumiai comenzaron a practicar a fines del siglo XVIII, en el territorio localizado entre la misión de San Fernando Velicatá y la de San Diego. Los franciscanos dejaron un espacio de $440 \mathrm{~km}$ sin atender; sin embargo, les era vital enviar sus correos o recuas para transportar víveres, utensilios y ganado de una misión a otra, por lo que tal distancia sin protección alguna hacía estas travesías sumamente peligrosas. Por lo tanto, fue necesario que continuamente se buscaran nuevas rutas (Neve, 1782) para evitar ser sorprendidos por los nativos, sobre todo por los que habitaban entre la Ensenada de Todos Santos y el arroyo de San Juan Bautista (actual poblado de La Misión).

En el año de 1771 en Ensenada, Fray Fernando Parrón y su escolta fueron frecuentemente acosados y atacados con piedras y flechas. En su informe asentó que los gentiles continuamente prendían fuego a los montes para obligarlos a meterse en emboscadas. Interesante resulta su documento al elogiar la habilidad de los kumiai para utilizar las hondas, que "ni la adarga ni la cuera" servían para protegerse de ellas. Pocos días después en Ensenada, fueron atacados tres soldados que venían de Velicatá y uno fue herido de gravedad con dos jaras (Expediente. . . 1772).

Pasados dos años los indígenas nuevamente atacaron al correo, y de acuerdo con el testimonio de los soldados de cuera, los gentiles les hicieron continuas salidas para impedirles el paso; "en el cajón de La Grulla . . . comenzaron a descargar piedras ... por lo que resolvieron volver". También agregaron que "no habían disparado un solo tiro. . porque uno tenía sólo una carga de pólvora, y tres balas el otro" (Ortega, 1774). En el informe de 1775, Felipe de Neve notificó al virrey que los gentiles habían atacado al correo a lo largo de 30 leguas, y que ya habían dispuesto que a partir del incidente, nadie atravesaría la ruta con menos de cinco soldados (Neve, 1775). Aún así, el 13 de agosto de 1777 los kumiai sorprenden a la escolta de la misión de San Diegoen el paraje de San Juan Bautista; Rivera y Moncada le informó a Neve lo siguiente: "estando 
parados haziendo noche . . como a 18 leguas de aquel presidio [de San Diego], dizen que Ramón Noriega se halló de centinela; que entretanto daba una vuelta a las mulas, los acometieron los gentiles. A los tres que dormían los hirieron, pero de muerte sólo el Cabo . . . lo sepultaron en el camino"(Neve, 1778).

En el paraje de Santa Rosalía, el 17 de agosto de 1780 se fundó la misión de San Vicente Ferrer. Tal hecho acortó la distancia entre San Diego y Velicatá, lo que vino a darle un respiro a la tropa. En 1781, como ya se señaló, fueron atacados los pueblos del Colorado con funestas consecuencias para la Nueva España. El éxito obtenido por los cuchán estimuló a los costeños y arremetieron con más frecuencia a los soldados. El 7 de septiembre de 1782, Neve le notifica a Fages que "no se ha podido pacificar a los gentiles entre San Diego y la frontera de la Baja California, particularmente los del Arroyo de San Juan Bautista, Encino y la Ensenada de Todos Santos ... han amenazado al correo ... . atacaron una recua de 50 mulas encargada al alférez Velázquez, 13 soldados y 4 arrieros". (Neve, 1782).

En el documento mencionado antes, se señala la necesidad de abrir un nuevo camino, el cual podría eliminar entre 10 y 12 leguas y además evitar las rancherías de la costa. José Velázquez fuecomisionado para abrir la nueva ruta, y mientras tanto, los ataques continuaban: un cabo relató su travesía de San Vicente a San Diego, durante la cual fue sorprendido por los indígenas, quienes le quitaron una mula para luego matarla (Zúñiga, 1782).

Otra noticia de interés en 1782 fue el censo de la misión de San Vicente, que dio como resultado la existencia de 14 familias, 83 personas, 6 caballos, 34 mulas, 6 burros, 56 reses, 114 ovejas, 27 cabras, 200 fanegas de trigo, 25 de cebada, 120 de maíz y 2 de frijol (Arrillaga, 1782). En cuanto a los militares, habia un sargento, 3 cabos, y 31 soldados (Canete, 1782).

Durante los años de 1783 y 1784 no hubo acontecimientos notables y los españoles los aprovecharon para cambiar los mandos de los sitios misionales. También los soldados de cuera fueron encuadrados en distintas misiones. Parece ser que esta estrategia estaba motivada por las frecuentes diferencias entre los frailes y la tropa, que se iniciaron entre el padre Serra y Pedro Fages, y continuaron entre éste y el padre Parrón.

El año de 1785 se inició con una intensa búsqueda de nuevos parajes para futuras misiones. El 7 de abril, Fages y Velázquez, con algunos soldados y varios indígenas como intérpretes, salieron de San Vicente y recorrieron La Calentura, Valle de la Trinidad, laguna Mecuata, y río Hardy (Forbes, 1975). El día 14 llegaron a una ranchería cucapá en donde descansaron algunos días para después dirigirse a Cerro Prieto. Algunas leguas más adelante se encontraron con una ranchería que había sido atacada por los cuchán Xuksil, quienes ya contaban con caballos para las guerras. Fages contó siete indígenas muertos, sus soldados y algunos más sin especificar el número (Forbes, 1975). Posteriormente, se dirigieron a las rancherías de San Sebastián y La Palma, de los kumiai del desierto, y el día 18 llegaron a la de San Felipe. De aquí Fages despachó a 
Velázquez para que regresara a La Palma, pues debido a la información obtenida de los indígenas, en esa ranchería se encontraban viviendo algunos kumiai de San Diego, quienes habían sido acusados de matar a un soldado desertor y a varios indigenas cristianos del área de San Diego (Forbes, 1975). Después del castigo que Velázquez creyó conveniente aplicar, él y sus doce soldados alcanzaron la columna, la cual arribó a San Diego el día 20 de abril. Fages anotó en sus relatos del viaje que los habitantes de La Palma habían dado muerte a ocho soldados, sin especificar más (Forbes, 1975).

El 4 de mayo en Arizpe, Sonora, Fages informó de su recorrido al comandante general Ugarte y Loyola, diciéndole también del registro del camino a La Grulla, el cual ahorraba 12 leguas y evitaba encontrarse con losindios playanos, siempre insolentes, atrevidos y de mala fe (Fages, 1785). Agrega que "no hay mejor sitio que ElEncino, entre San Diego y San Vicente, para nueva misión",y que "ha recomendado dar a San Diego 11 soldados y un sargento, porque las tres fronteras establecidas están aún rodeadas de numerosa gentilidad" (Fages, 1785). El viaje de Pedro Fages sería el último que realizarían los españoles en el área del Colorado por espacio de diez años.

El dominico Luis de Sales realizó varias expediciones en 1786 para localizar un sitio intermedio entre San Vicente y San Diego, y en cada uno fue duramente acometido por los kumiai. En varias ocasiones resultó herido; en una, por una piedra disparada por una honda que le dislocó un hueso; y en otra, huyendo junto con los soldados al ser sorprendido por los nativos, cayó de su caballo y éste encima de él, que a la postre le salvó la vida sirviéndole de escudo y escondiéndolo (Sales, 1960).

\section{Fundación de San Miguel Arcángel}

El 3 de enero de 1787 llegaron noticias a San Vicente de que los indígenas del río Colorado pensaban atacar la misión. El 5 de marzo, Fages envió instrucciones a Monterrey para que "se provea de bestias a 6 soldados de la Compañía de Loreto que han de ir destacados a la fundación del Encino, al mando del Sargento Ygnacio Alvarado, que en su primer viaje deben de transportar 30 fanegas de maíz y 4 de frijol, 2 tercios de harina, manteca y sebo; cartuchos y municiones, pólvora y balas; que los quecompongan el destacamento deben ser mozos aguerridos [y] que remita el esmeril o pedrerito tan luego venga de Santa Bárbara" (Fages, 1787a).

Estas providencias se tomaban porque continuaban los rumores acerca de que para el verano los indígenas del Colorado y los kumiaide la montaña y de la costa, atacarían la misión de San Vicente; por tanto, la fundación de San Miguel Arcángel de la Frontera tendría que llevarse a cabo con todas las precauciones militares y bajo una vigilancia continua con indígenas de la confianza de los misioneros. Ahora los novohispanos, por vez primera, aprovecharían el sistema de centinelas y correos que con tanta excelencia mantenían siempre alerta a los kumiai. 
Mientras tanto, Pedro Fages, el padre Sales, doce soldados, variosindígenas cristianos de San Vicente y una gran cantidad de ganadollegaron el 28 de marzo al sitio señalado para levantar la misión(Fages, 1787c), pero para su desilusión, las lluvias de invierno habían impedidoel uso de los ojos de agua; sin embargo, se decidió no volver a San Vicente hasta encontrar otro sitio y éste fue localizado en el arroyo de La Encina. Sales comentó sobre este paraje que "aunque de pocas proporciones, podía servir por lo pronto. . ." (Sales, 1960).

El 12 de mayo llegó a la nueva misión el teniente Ortega, quien decidió ponerla en estado de sitio, debido al informe proporcionado por el sargento, quien le comunicó que "había sabido por los gentiles que los del Carmen, Ensenada, la Sierra, el Valle y otros, se iban juntanto para caer a la misión" (Ortega, 1787a). Ortega, sin perder tiempo, "mandó hacer un cuadro de 60 varas por 50 varas con dos opuestos baluartes de adobe. . .". Seguido dio instrucciones al cabo para que con cinco soldados salieran diariamente a buscar indígenas para que los tuvieran al corriente de los sucesos, y después de "sentarles la mano", como el mismo Ortega dice, los dejaban ir para que avisasen a los demás que los soldados estarian esperando a los indígenas que no admitían la paz y que estaban decididos a "poblar el campo como piedras con indios muertos para que coyotes y pájaros los comieran (Ortega, 1787,b). Ya estaba claro que el ataque no sería dirigido a San Vicente, sino a San Miguel Arcángel.

A los pocos días, y ante la necesidad que algunos indigenas tenían de regresar a San Vicente, de Sales le solicitó la escolta a Ortega, quien ordenó a dos soldados que escoltasen a los nativos hasta el Maneadero y que volviesen de inmediato. Al llegar a Ensenada se detuvieron para dar agua a sus caballos, cuando oyeron gritos de cinco nativos que venían armados. Los soldados subieron a sus cabalgaduras con el propósito de huir, y uno de los soldados fue derribado al recibir un golpe, mientras el otro golpeó al indígena, y tras una pequeña trifulca lograron dominarlo y llevarlo a la misión de San Miguel. Ahí éste declaró que los indígenas tendrían una reunión arriba de Ensenada; entonces Ortega decidió mandar a un cabo con seis soldados y dos intérpretes de regreso a Ensenada, para que se entrevistaran con los cabecillas de la insurrección y, de ser posible, remitirlos a la misión. Estos salieron de noche procurando llegar a todas las rancherías que les fuese posibie, pero una a una las fueron encontrando desiertas; decidieron volver, $\mathrm{y}$ al extraviarse en una espesa neblina, de pronto se encontraron en una ranchería. Por medio de los intérpretes les hicieron saber el mensaje del teniente Ortega, pero al parecer éste no impresionó a los kumiai, quienes respondieron "que ellos también serían de los que caerían a matar soldados y que no tenían miedo"(Ortega, 1787b). El cabo, sorprendido por la altanería de los nativos, trató de reprenderlos, pero al darse cuenta de que su esfuerzo de nada servía, mandó azotar a los que consideró más atrevidos y se llevó al jefe de regreso a la misión.

Llegados a San Miguel, Ortega inmediatamentese dio a la tarea de sacar toda la información posible al indigena, quien con ayuda de un neófito, respondió dando nombres "de más de 50 rancherías del Carmen, Tigre, Ensenada, el Valle y la Sierra de San Juan Bautista"(Ortega, 1787a). Siguió diciendo que 
"todas estaban listas para atacar la misión en la luna nueva y acabar con todos y llevarse la caballada, ganado, ropa y todo cuanto había" (Ortega, 1787a).

El comandante de San Miguel se entrevistó con Luis de Sales y convinieron en enviar de nueva cuenta a la tropa para que ésta se dedicara a amedrentar las rancherías y disuadirlos de sus intentos de atacar la misión. Así los soldados diariamente ejecutaban recorridos por El Tigre y El Carmen, esperando ganar tiempo para caer después sobre Ensenada, por considerar que desde ahí se estaba organizando la resistencia indígena. Además, los militares ya habían sido informados que los kumiai de la bahía estaban enviando continuamente mensajeros al río Colorado para reafirmar sus alianzas y asegurarse de que vendrían el día señalado y que les auxiliarían en su plan.

En la madrugada del 26 de mayo de 1878, los soldados cayeron sobre la ranchería de Ensenada, pero ya los estaban esperando, por lo que el ataque sorpresivo que pretendieron fue un fracaso. Los indigenas, de acuerdo con el cabo Ortega, "estaban amparados en barrancos y espesos bosques". Aún así lograron sorprender al kulpay cuatay y al cusiay cuatay, es decir, al jefe de guerra y al hechicero mayor, logrando detenerlos. De todas maneras, dice nuevamente Ortega, el gran hechicero los seguía alentando a que peleasen, y que él, "con una yerba, acabaría con la tropa"(Ortega, 1787b).

Teniendo ya cautivos a estos dos principales convocadores de aquel congreso, Ortega resolvió regresar a la misión, llevándose a sus prisioneros que fueron azotados e interrogados, aceptando tener en alianza a 24 rancherías, y que los del "Médano y Barrabás" también querían caer junto con ellos a la misión, admitiendo que había invitado a los indígenas del río Colorado. Durante los tres siguientes días los soldados se dedicaron a visitar y castigar a las rancherías al norte de San Miguel Arcángel, y todos señalaban a los de Ensenada como principales convocadores para matar soldados y frailes. Ya restablecida la calma, De Sales se dedicó a los trabajos de construcción de casas y se iniciaron las siembras. Se llevó a cabo el bautizo de dos niñas, contándose con el auxilio de cinco indígenas de esa región (Ortega, 1787b).

Aún así, los soldados continuaban en estado de alerta y sus recorridos eran con la misma frecuencia. En uno de éstos, el cabo Acevedo trajo detenido al capitán de la sierra, quien pronto fue enviado a la misión de San Diego en donde se encontraban sus cómplices, los cabecillas de Ensenada. Es pertinente aclarar que la tropa que se encontraba en San Miguel dependía de la comandancia del presidio de San Diego por instrucciones del gobernador Fages, razón por la cual los indigenas prisioneros se encontraban allí y no en San Vicente Ferrer.

Transcurrieron los días ya casi sin novedad alguna, cuando la misión se quedó sin agua y el fraile Luis de Sales comenzó afanosamente a buscar un mejor sitio para su misión. La fortuna no lo hizo esperar mucho, pues andando por una vereda, según testimonio, "apareció un indígena con una mordedura de víbora y con algunos aceites pudo aliviarse" (Sales, 1960). Este kumiai agonizante resultó ser el jefe de la ranchería deSan Juan Bautistay, cuando ya restablecido 
convidó a Sales a visitarlo y después de haber reconocidoel paraje, no dudó un solo instante e inmediatamente decidió levantar la misión en ese sitio, quedando ahí para la historia San Miguel Arcángel de la Frontera. El general Ugarte y Loyola, comandante de las Provincias Internas, aprobó el nuevo establecimiento con fecha 14 de septiembre de 1788. En el mismo documento, dio su autorización para que los cabecillas de la insurrección quedaran en libertad, después de castigarlos ligeramente.

Este evento marcó el término de la insurrección indígena de los kumiai de la costa guiados por los de Ensenada, convertida en foco de resistencia indígena a partir de la fundación de San Vicente Ferrer en 1780. Los años restantes del siglo XVIII transcurrieron en relativa calma, salvo algunos incidentes aislados.

Para cerrar este episodio queremos citar las impresiones de Pedro Fages, gobernador de la Antigua California, que tenía en su hoja de servicios 18 años combatiendo indígenas en las dos Californias y en el río Colorado:

Esta nación, es entre las que se han descubierto, la más numerosa, también la más agitada, bronca y orgullosa, aguerrida y nuestra peor enemiga... siempre se han mostrado con un espíritu de independencia". 


\section{BIBLIOGRAFIA}

ARRILLAGA, José J. de. 1782. "Carta de José Joaquín de Arrillaga a Pedro Fages”. Loreto, 31 de diciembre de 1782. California Archives. Vol. 50, p. 20. Bancroft Library. Berkeley, Ca.

BURRUS, Ernest J. 1967. Diario del capitán comandante Fernando de Rivera y Moncada. Colección Chimalistac, 25. Ed. José Purrúa y Turanzas, Madrid.

CANETE, J. 1782. Carta de J. Canete a Pedro Fages. Loreto, 1ㅇ de octubre de 1782. California Archives, vol. 15, p. 102 Bancroft Library. Berkeley, California.

1772. Expediente Sobre el Mejor Establecimiento de las Nuevas Misiones de California y Subsistencia de las Antiguas de Aquella Península, № 4. Provincias Internas 152. Archivo General de la Nación. México, D.F.

FAGES, Pedro. 1785. "Carta de Pedro Fages al Gral. Ugarte y Loyola". San Gabriel, 4 de mayo de 1785. California Archives, vol. 22, p. 191. Bancroft Library. Berkeley, Calif.

1787a. "Informe general sobre misiones 1787". California Archives, 52. Bancroft Library. Berkeley, Calif.

1787b. "Carta de Pedro Fages aZúñiga”, Monterey, 5 de marzo de 1787. California Archives, vol. 23, p. 262. Bancroft Library. Berkeley, California. 1787c. "Carta de Pedro Fages a Joaquín José de Arrillaga", Monterey, 20 de junio de 1787. California Archives, vol. 4 p. 18. Bancroft Library. Berkeley, Calif.

FORBES, Jack D. 1975. The Yumans of the Qhuechan Nation and their Neighbors. University of Oklahoma Press. Norman.

GOMEZ Canedo, Lino. 1969. De México a la Alta California. Colección México Heroico. Ed. Jus. México, D.F.

LUOMALA, Katherine. 1978. "Tipai-ipai”. Handbook of North Americans Indians, vol. 8. Robert F. Heizer (ed). Smithsonian Institution, Washington, D.C.

MEIGS, Peveril. 1936. The Dominican Frontier of Lower California. University of California Press. Berkeley, California.

NEVE, Felipe de. 1775. "Carta de Felipe de Neve al virrey Bucareli". Loreto, 6 de agosto de 1775. California Archives, vol. 22, p. 145. Bancroft Library. Berkeley, California.

1778. "Carta de Felipe de Neve a Teodoro D. Crox, comandante general de las Prov. Laterales de Occidente”. Monterey, 15 de abril de 1778. California Archives, vol. 22, p. 97. Bancroft Library. Berkeley, Calif. 1782. "Carta de Felipe de Neve a Pedro Fages". El Saucito, 7 de septiembre de 1782. California Archives, vol. 2, p. 131. Bancroft Library. Berkeley, Calif.

ORTEGA, Francisco. 1774. "Carta del teniente Francisco Ortega al capitán Rivera y Moncada”. San Diego, 5 de mayode 1774. California Archives, vol. 1. Bancroft Library. Berkeley, California.

1787a. "Carta de Francisco Ortega a Pedro Fages". San Diego, 19 de

mayo de 1787. Califormia Archives, vol. 4, pp. 83-85. Bancroft Library. Berkeley, California. 
1787b. "Carta de Francisco Ortega a Pedro Fages". San Diego, 5 de junı de 1787. California Archives, vol. 4, p. 79. Bancroft Library. Berkeley, California.

OWEN, Robert C. 1966. The Social Evolution of Northern Baja California Indians. $4^{0}$ Simposium, Asociación Cultural de las Californias, Costa Mesa, California.

SALES, Luis de. 1960. Noticias de la Provincia de la California. Colección Chimalistac. José Porrúa Turanzas, Ed. Madrid.

SHIPEK, Florence C. 1982. "Kumeyaay Socio-Political Structure". Journal of California and Great Basin Anthropology, vol. 4, № 2.

VERGER, 1771. "Carta del padre Verger a Manuel de Casafonda, fiscal del Consejo de Indias”. Segunda serie, vol. XV. Archivo General de la Nación, Méxiço, D.F.

ZARATE Loperena, D. 1987. "Indígenas de Baja California". En: Memoria del Cuarto Simposium de Historia Regional "Antonio Meléndrez". Gobierno del Estado de Baja California. 